\title{
Study of epidemiological, clinical and evolutionary characteristics of a population of patients hospitalized for COVID-19 in Morocco
}

\author{
Jaafar Heikel ${ }^{1,9}$, Hasnae Benkirane ${ }^{2,9}$, Fadoua Ballouk ${ }^{2,9}$, Amina Bouziani $^{2 *}$, Fatima Zahra Laamiri $^{3}$, Houria Lahmam $^{2}$, \\ Majdouline Obtel $^{4}$, Noureddine El Haloui ${ }^{2}$, Khalid Ennibi ${ }^{5}$, Naim Akhtar Khan ${ }^{7}$, El Mostafa El Fahime ${ }^{7,9}$, Majida \\ Zahraoui $^{1,9}$, Hassan Aguenaou ${ }^{2,9}$ and Amina Barkat ${ }^{8,9}$ \\ ${ }^{1}$ Mohammed 6 University of Health Sciences, Casablanca-Morocco; \\ ${ }^{2}$ Ibn Tofail University-CNESTEN, Joint Research Unit in Nutrition, Health and Environment, RDC-Nutrition AFRA/IAEA, \\ Laboratory Biology and Health, 14000 Kenitra, Morocco; \\ ${ }^{3}$ Hassan First University of Settat, Higher Institute of Health Sciences of Settat, Laboratory of Health Sciences and \\ Technology, Morocco; \\ ${ }^{4}$ Laboratory of Community Health, Preventive Medicine and Hygiene \& Laboratory of Epidemiology and Clinical \\ Research, Department of Public Heath, Faculty of Medicine and Pharmacy, University Mohammed V in Rabat; \\ ${ }^{5}$ Center of Virology, Infectious and Tropical Diseases, Mohammed V Military Hospital, Rabat, Morocco; \\ ${ }^{6}$ Inserm Research Center, U1231 INSERM/UB/AgroSup, Team-Physiology of Nutrition \& Toxicology, University of \\ Bourgogne Franche-Comté (UBFC), Faculty of Life Sciences, 6 Boulevard Gabriel, 21000 Dijon, France; \\ ${ }^{7}$ Functional Genomic Platform, UATRS-CNRST. Rabat, Morocco; \\ ${ }^{8}$ Health and Nutrition Research Team of the Mother-Child Couple, Faculty of Medicine, Mohammed $5^{\text {th }}$ University. 10100. \\ Rabat. Morocco; barakatamina@hotmail.fr \\ ${ }^{9}$ Moroccan society of nutrition, health and environment-Casablanca, Morocco;
}

\begin{abstract}
The outbreak of COVID-19 still represents a real risk for the increased death rate for the whole of human kind. In this context, the present research work aims at describing evolutionary data in a population of hospitalized COVID-19 positive patients based on selected epidemiological, clinical and paraclinical data at admission. In this cross-sectional study, we examined the data obtained from 108 patients hospitalized with COVID-19 in the VINCI clinic, Casablanca (Morocco) between August and September 2020. General characteristic, clinical, radiological and biological data as well as therapeutic management were assessed. The patients' median age was 45-50 years old. Among our studied patients, $4.6 \%$ were transferred to the intensive care unit (ICU), $16.7 \%$ were cured after more than 15 days, while $78.7 \%$ were cured within 15 days. Those transferred to the ICU unit were either smokers, obese, or over 65 years of age. The majority of patients with normal radiological and cardiac parameters were cured within $<15$ days, while biological disorders were observed in approximately all cases that were transferred to ICU. Regarding therapeutic treatment, $98.1 \%$ of the subjects were treated with hydroxychloroquine + azithromycin in combination with vitamin $C$ and zinc supplementation. The study shows that the minimal healing time is well conditioned by the general and clinical characteristics of patients. Furthermore, the administration of hydroxychloroquine + azithromycin showed a beneficial effect with no associated adverse effects in the study cases.
\end{abstract}

Keywords: COVID-19; Clinical; biological characteristics; Chest computed tomography; Followup data; Hydroxychloroquine

\section{Introduction}

The COVID-19 epidemic, caused by the SARS-CoV2 virus, continues to progress and represents a real health danger for humanity [1]. Faced with this new pandemic, health authorities across the world have been mobilized to support government efforts, both through their intervention in the care of patients and the search for effective treatments [2].

Continuous clinical monitoring of affected patients reveals a range of symptoms associated with this disease. The most common ones are represented by fever, cough, myalgia and anosmia and/or ageusia [3] as well as severe acute respiratory distress syndrome and pneumonia in critical cases [4]. Moreover, studies on clinical outcomes have demonstrated a positive association of several factors with disease severity namely older age and preexisting comorbidities such as cardiovascular diseases. These conditions are associated with development of greater severity of respiratory disorders or pneumonia [5], leading to hospital admissions and poor clinical outcomes. In younger patients, gender, body mass index and cancer history represent independent predictors of in-hospital mortality [6].

\footnotetext{
Corresponding author: amina.bouziani@uit.ac.ma
} 
In regard to the COVID-19 patients' therapeutic management, approaches vary considerably according to the severity of the infection, the patient's age, gender, and medical history [7]. Currently, various treatment protocols for COVID-19 patients have been proposed, and several candidate vaccines have been developed in a preventive context. Nonetheless, many potential drugs have been proposed and tested for their efficiency against SARS-Cov-2 infection, notably, angiotensin converting enzyme inhibitors and/or receptor blockers, anti-inflammatory agents, nucleoside analogs, protease inhibitors, monoclonal antibodies, the use of convalescent plasma [2] and antiviral drugs [8]. Importantly, it has been proven through randomized, controlled clinical trials, that antiviral treatments such as remdesivir, lopinavir-ritonavir, hydroxychloroquine, and those based on the use of antibodies are safe and effective therapies during the early stages of viral replication $[8,9]$. However, studies have been unable to demonstrate clearly that remdesivir and lopinavir/ritonavir can provide successful disease treatment and reduce mortality rates. Interestingly, more successful outcomes have been demonstrated for hydroxychloroquine and its efficacy in reducing viral vulnerability [10] especially when used at an early stage before developing other complications and decreasing the spread of the virus [11]. Additionally, the effect of hydroxychloroquine on reducing mortality rate, principally when associated with azithromycin has also been largely reported [12].

However, results from many randomized control trials and from the WHO SOLIDARITY trial, conducted in hospitalized patients with COVID-19 in several countries, showed that these antiviral drugs (remdesivir, lopinavir-ritonavir and hydroxychloroquine), have little or no effect on overall mortality, on the application of mechanical ventilation, and on the length of the hospital stay $[13,14]$. They may even cause adverse side effects particularly for remdesivir and lopinavir-ritonavir including serious gastrointestinal adverse events and also hypoalbuminaemia, hypokalaemia, anaemia, thrombocytopenia, and increased total bilirubin $[15,16]$. Moreover, there is a lack of supporting data on side effects hydroxychloroquine in the treatment for COVID19 [117] and its use remains controversial since the results of the various large randomized controlled trials have shown no positive effects of this treatment.

In parallel, other potential adjuvants against SARSCov-2 infection, such as zinc and vitamin D have been recommended, via experimental and in vitro studies in COVID-19 patients, for their intervention in strengthening the immune system and avoiding the cytotoxicity of chloroquine $[18,19]$. The introduction of vitamin $\mathrm{C}$ in the treatment of COVID-19 patients has also been proposed [20]. Interestingly, the administration of a high dose of vitamin $\mathrm{C}$ in a group of infected patients has been shown to be effective in reducing the risk of 28-day mortality compared to a control therapy group [21]. Concerning vitamin D, several previous studies confirmed the inverse correlation between the 25OHD levels and the clinical outcomes of COVID-19 [22]. There are other therapies that have also been widely adopted, including oxygen therapy for hypoxemia [23], administration of antibiotics [24], anticoagulant treatment [25], all of which help reduce disease complications and improve survival of COVID19 patients especially, those that have been transferred to the Intensive Care Unit (ICU).

In light of limited studies in Morocco and to strengthen the efforts made by researchers to provide more findings in relation to COVID-19 patients, the present work has been conducted to study the clinical progression of a sample of Moroccan patients affected by SARS-Cov-2 virus and to describe the therapeutic management. The objective of this study is to describe evolutionary data in a population of hospitalized COVID-19 positive patients based on selected epidemiological, clinical and paraclinical data at the time of admission.

\section{Materials and Methods}

\subsection{General Study design}

The present study used a data-set obtained from a descriptive and non-interventional cross-sectional study that was conducted the VINCI clinic in Casablanca (Morocco) on COVID-19 patients, in partnership with the research team of maternal and child health and nutrition, the faculty of medicine and pharmacy, the University Mohammed V, Rabat (Morocco) as well as the Ministry of Health and the National Center for Scientific and Technical Research, Rabat.

Data collection was done using a validated questionnaire by medical staff assigned to COVID-19 patients who were part of the medical monitoring team and the necessary therapeutic protocol for each subject in terms of an evolutionary study of patients' health status.

\subsection{Subjects}

A total of 108 patients diagnosed with COVID 19 and admitted to the VINCI clinic were collected during August and September 2020. All participants were adult patients, men and women, aged $\geq 18$ years, confirmed to be COVID-19 positive and who gave signed consent. Patients allergic to any of the drugs, specifically chloroquine and hydroxychloroquine, pregnant women, patients suffering from serious diseases (cardiovascular disorders, lung damage, renal dysfunction, head disorders, blood diseases and other dysfunctions) were not included in the study [26].

\subsection{Description of the study protocol}

Data was collected by the medical staff specific in the VINCI clinic who were part of the team treating COVID-19 and according to the following procedures:

\subsubsection{Laboratory confirmation}

COVID-19 positive patients were identified from laboratory tests using real-time polymerase chain reaction (RT-PCR) on nasopharyngeal/oropharyngeal samples and chest radiographic examinations. The RTPCR test was performed based on the "Berlin protocol" [27].

\subsubsection{Collection of general parameters}

From each included patient, demographic data including age, sex, tobacco or alcohol consumption and comorbidities were noted. Anthropometric measurements (weight, height and Body Mass index (BMI)) were performed depending on standard 
procedures described by the World Health Organization (WHO) [28]. Moreover, the presence of symptoms, specific to Sars-CoV-2 infection, and the source of contamination were noted.

\subsubsection{Medical monitoring and therapeutic protocol}

\subsubsection{Biological analysis}

The blood tests carried out focused on the measurement of the following parameters: hepatic markers (aspartate aminotransferase (AST), alanine aminotransferase (ALT), gamma-glutamyl transpeptidase (GGT)), lactate dehydrogenase (LDH), procalcitonin, troponin, lymphocytes, platelets, prothrombin time $(\mathrm{PT}), \mathrm{C}$ reactive protein (CRP) and ferritin. The analysis of each parameter was carried out following the procedure adopted in the laboratory of the Pasteur's Institute in Casablanca. Based on specific laboratory techniques, these parameters have been carefully measured [3].

\subsubsection{Chest computed tomography (CT)}

Upon admission, patients suspected of COVID-19 infection underwent a chest computed tomography using a multi-bar scanner device (United UCT 528). Two major chest CT classification scales for standardized CT reporting of COVID-19 have been developed, namely the COVID-19 Reporting and Data System (CO-RADS) and Radiological Society of North America classification system for reporting COVID-19 pneumonia [29]. For this study, CO-RADS score was used to quantify the extent and severity of the infection in the lungs.

The analysis of the obtained images was carried out by a specific software allowing the determination of the territory presenting pulmonary opacities.

\subsubsection{Image analysis}

COVID-19 usually shows up on CT as bilateral frosted glass and consolidating lung opacities. Radiologists categorized their observations from thinfilm CT scans (United imaging (uCT 528)) according to the distribution of opacities to define the severity of lung involvement.

\subsubsection{Electrocardiogram}

On admission, a cardiac examination was performed for each patient. The principle of the electrocardiogram (ECG) was based on an electrophysiological recording whose trace materializes the electrical activity of the heart. The capture of this activity is carried out using electrodes which are placed on the surface of the body.

For each case, the measurement, diagnosis and interpretation of the electrical tracing have been realized, independently, by specialized and experienced cardiologists.

\subsubsection{Treatment procedure}

The therapeutic treatment adopted is strictly in accordance with the recommendation of the national scientific and technical committee of the Ministry of Health. It involves the use of hydroxychloroquine and azithromycin, as the main treatment, in addition to a series of medical interventions based on oxygen, antibiotics, corticosteroids, and antiplatelet therapies, and on the administration of other adjuvants such as vitamin $\mathrm{C}$, vitamin $\mathrm{D}$, zinc sulfate and low molecular weight heparin [30,31].

\subsection{Statistical analysis}

The Kolmogorov-Smirnov test was used to study the normality of the distribution of the different variables. Measurements conforming to the normal distribution were expressed as mean \pm standard deviation while data not following a normal distribution are described by the median (Quartiles). The qualitative data were described by the number of cases and the percentage (n (\%)). The age was presented using the median (interquartile interval), while all the other qualitative variables were presented using the total number and percentage with the confidence interval.

The comparative analysis of qualitative variables was performed by using Chi-square and the Fisher test according of the applicability conditions of the tests. A $p$-value $<0.05$ was considered statistically significant.

Data analysis was performed using SPSS software version 13.0.

\subsection{Ethics}

This study was conducted after the Ethical Committee and Biomedical Research of the College of Medicine and Pharmacy of Mohammed 5th University (Rabat, Morocco) approved the use of patients' data and their analysis (Approval number: 17/20, delivered on $12 / 06 / 2020$ ) and is a part of an overall project on the COVID-19 pandemic. Further, written informed consent was obtained from all eligible patients after providing them with the objectives and details of the study.

\section{Results}

\subsection{Follow-up data}

\subsubsection{Follow-up data according to general characteristics (Table 1)}

Among the 108 COVID-19 positive patients admitted in the clinic, $4.6 \%$ were transferred to the ICU, $16.7 \%$ were cured after more than 15 days while $78.7 \%$ were cured in less than 15 days. The analysis of patients' distribution in relation to the follow-up data revealed a statistically significant difference according to age $(p=0.046)$ and BMI $(p=0.028)$. Indeed, we noted the following observations:

- The percentage of patients with a healing time of less than 15 days was significantly higher in those under 65 years of age $(p=0.046)$;

- All of the patients transferred to the ICU were smokers and the majority of cases $(92.9 \%)$ who were cured in less than 15 days were not tobacco users;

- More than half of the patients transferred to the ICU $(60 \%)$ were obese and the percentage of patients with a recovery time of less than 15 days had a normal BMI $(p=0.028)$.

However, no statistically significant difference was observed concerning the distribution of patients according to gender, alcohol consumption and finally to the presence or not of comorbidity and/or symptomatology. 
Table 1. Distribution of patients according to general admission and follow-up data

\begin{tabular}{|c|c|c|c|c|}
\hline \multirow[t]{2}{*}{ Variables } & \multicolumn{3}{|c|}{ Follow-up data $(n=108(\%))$} & \multirow[t]{2}{*}{$p^{*}$} \\
\hline & $\begin{array}{l}\text { Transfer } \\
\text { to ICU } \\
n=5\end{array}$ & $\begin{array}{c}\text { Healing } \\
\text { Time } \\
>15 \text { days } \\
n=18\end{array}$ & $\begin{array}{c}\text { Healing } \\
\text { Time }<15 \\
\text { days } \\
\mathbf{n}=85\end{array}$ & \\
\hline Sex & & & & 0.366 \\
\hline Male & $4(80)$ & $10(55.6)$ & $40(47.1)$ & \\
\hline Female & $1(20)$ & $8(44.4)$ & $45(52.9)$ & \\
\hline Age groups (years) & & & & 0.046 \\
\hline$(18-35)$ & $1(20)$ & $5(27.8)$ & $29(34.1)$ & \\
\hline$(35-45)$ & $1(20)$ & $6(33.3)$ & $10(11.8)$ & \\
\hline$(45-55)$ & $0(0)$ & $6(33.3)$ & $20(23.5)$ & \\
\hline$(55-65)$ & $2(40)$ & $0(0)$ & $18(21.2)$ & \\
\hline$\geq 65$ & $1(20)$ & $1(5.6)$ & $8(9.4)$ & \\
\hline BMI groups & & & & 0.028 \\
\hline normal & $2(40)$ & $11(61.1)$ & $48(56.5)$ & \\
\hline Overweight & $0(0)$ & $7(38.9)$ & $23(27.1)$ & \\
\hline Obesity & $3(60)$ & $0(0)$ & $14(16.6)$ & \\
\hline Tobacco & & & & 0.038 \\
\hline No & $0(0)$ & $13(72.2)$ & $79(92.9)$ & \\
\hline Yes & $5(100)$ & $5(27.8)$ & $6(7.1)$ & \\
\hline Alcohol & & & & 0.405 \\
\hline No & $4(80)$ & $13(72.2)$ & $72(84.7)$ & \\
\hline Yes & $1(20)$ & $5(27.8)$ & $13(15.3)$ & \\
\hline Comorbidity & & & & 0.158 \\
\hline No & $2(40)$ & $15(83.3)$ & $60(70.6)$ & \\
\hline Yes & $3(60)$ & $3(16.7)$ & $25(29.4)$ & \\
\hline Symptomatology & & & & 0.626 \\
\hline No & $2(40)$ & $5(27.8)$ & $20(23.5)$ & \\
\hline Yes & $3(60)$ & $13(72.2)$ & $65(76.5)$ & \\
\hline
\end{tabular}

Note: The values are expressed in numbers and percentage ( $n$ (\%)). * Exact fisher test.

\subsubsection{Radiological and biological findings}

The radiological examination on admission showed that the CT scan was normal in $37 \%$, with unsystematic ground glass opacities in 59.3\% and finally with extensive alveolar condensation in $3.7 \%$. In addition, the ECG was normal in the majority of patients. Analysis of patients' distribution according to radiological parameters at admission (Table 3) revealed that the percentage of patients who were cured in less than 15 days was significantly higher in patients with normal CT scan $(p=0.001)$ and normal ECG $(p=0.028)$ at admission.

Analysis of the distribution, according to biological parameters and follow-up data (Table 2) showed that in the group transferred to the ICU, the level of GGT and LDH was high in $100 \%$ and $80 \%$ of patients respectively. Lymphocytes and platelets levels were low in $60 \%$ and $40 \%$ of the patients respectively, and finally, CRP and ferritinemia levels were also high in 100\% and $80 \%$ of the patients respectively.

On the other hand, we observed a statistically significant difference in the distribution of the serum level of GGT, CRP and ferritin according to the healing time (Table 2). In contrast, no statistically significant difference was noted for the other parameters namely AST, ALT, LDH, lymphocytes, platelets, procalcitonin, troponin and prothrombin time.

Table 2. Comparisons of follow-up data according to radiological and biological results

\begin{tabular}{|c|c|c|c|c|}
\hline \multirow[t]{2}{*}{ Variables } & \multicolumn{3}{|c|}{ Follow-up data $(n=108(\%))$} & \multirow[t]{2}{*}{$p^{*}$} \\
\hline & $\begin{array}{l}\text { Transfer } \\
\text { to ICU } \\
n=5\end{array}$ & $\begin{array}{c}\text { Healing } \\
\text { time }>15 \\
\text { days }\end{array}$ & $\begin{array}{c}\text { Healing } \\
\text { time }<15 \\
\text { days }\end{array}$ & \\
\hline
\end{tabular}

\begin{tabular}{|c|c|c|c|c|}
\hline & & $n=18$ & $n=85$ & \\
\hline \multicolumn{5}{|c|}{ Radiological data on admission } \\
\hline CT chest & & & & 0.001 \\
\hline Normal & $0(0)$ & $7(38.9)$ & $33(38.8)$ & \\
\hline $\begin{array}{l}\text { Unsystematic } \\
\text { ground glass } \\
\text { opacities }\end{array}$ & $2(40)$ & $11(61.1)$ & $51(60)$ & \\
\hline $\begin{array}{l}\text { Extensive } \\
\text { alveolar } \\
\text { condensations }\end{array}$ & $3(60)$ & $0(0)$ & $1(1.2)$ & \\
\hline ECG & & & & 0.028 \\
\hline Normal & $3(60)$ & $17(94.4)$ & $82(96.5)$ & \\
\hline Abnormal & $2(40)$ & $1(5.6)$ & $3(3.5)$ & \\
\hline \multicolumn{5}{|c|}{ Biological data on admission } \\
\hline AST & & & & 0.307 \\
\hline$<40 U I / I$ & $3(60)$ & $16(88.9)$ & $72(84.7)$ & \\
\hline$>40 \mathrm{UI} / \mathrm{I}$ & $2(40)$ & $2(11.1)$ & $13(15.3)$ & \\
\hline ALT & & & & 0.294 \\
\hline$<41 \mathrm{UI} / \mathrm{I}$ & $3(60)$ & $16(88.9)$ & $68(80)$ & \\
\hline$>41 \mathrm{UI} / \mathrm{I}$ & $2(40)$ & $2(11.1)$ & $17(20)$ & \\
\hline GGT & & & & 0.041 \\
\hline$<60 \mathrm{UI} / \mathrm{I}$ & $0(0)$ & $18(100)$ & $79(92.9)$ & \\
\hline$>60 \mathrm{UI} / \mathrm{I}$ & $5(100)$ & $0(0)$ & $6(7.1)$ & \\
\hline LDH & & & & 0.071 \\
\hline$<225 \mathrm{UI} / \mathrm{I}$ & $1(20)$ & $11(61.1)$ & $58(68.2)$ & \\
\hline$>225 \mathrm{UI} / \mathrm{I}$ & $4(80)$ & $7(38.9)$ & $27(31.8)$ & \\
\hline Procalcitonin & & & & 0.158 \\
\hline$<0.5 \mathrm{mg} / \mathrm{ml}$ & $5(100)$ & $17(10)$ & $82(96.5)$ & \\
\hline$>0.5 \mathrm{mg} / \mathrm{ml}$ & $0(0)$ & $0(0)$ & $3(3.5)$ & \\
\hline Troponin & & & & 0.094 \\
\hline$<14 \mathrm{ng} / \mathrm{l}$ & $4(80)$ & $15(83.3)$ & $80(95.2)$ & \\
\hline$>14 \mathrm{ng} / \mathrm{l}$ & $1(20)$ & $3(16.7)$ & $4(4.8)$ & \\
\hline Lymphocytes & & & & 0.272 \\
\hline Low & $3(60)$ & $5(27.8)$ & $18(21.2)$ & \\
\hline Normal & $2(40)$ & $13(72.2)$ & $66(77.6)$ & \\
\hline High & $0(0)$ & $0(0)$ & $1(1.2)$ & \\
\hline Platelets & & & & 0.120 \\
\hline Low & $2(40)$ & $5(27.8)$ & $9(10.6)$ & \\
\hline Normal & $3(60)$ & $13(72.2)$ & $73(85.9)$ & \\
\hline High & $0(0)$ & $0(0)$ & $3(3.5)$ & \\
\hline $\operatorname{TP}(n=103)$ & & & & 0.388 \\
\hline Low & $1(20)$ & $0(0)$ & $6(7.5)$ & \\
\hline Normal & $3(60)$ & $16(88.9)$ & $62(77.5)$ & \\
\hline High & $1(20)$ & $2(11.1)$ & $12(15)$ & \\
\hline CRP & & & & 0.007 \\
\hline$\leq 5 \mathrm{mg} / \mathrm{l}$ & $0(0)$ & $14(77.8)$ & $55(64.7)$ & \\
\hline$>5 \mathrm{mg} / \mathrm{l}$ & $5(100)$ & $4(22.2)$ & $30(35.3)$ & \\
\hline Ferritin & & & & 0.009 \\
\hline$<30 \mathrm{ng} / \mathrm{ml}$ & $0(0)$ & $2(11.1)$ & $11(12.9)$ & \\
\hline $30-400 \mathrm{ng} / \mathrm{ml}$ & $1(20)$ & $15(83.3)$ & $64(75.3)$ & \\
\hline$>400 \mathrm{ng} / \mathrm{ml}$ & $4(80)$ & $1(5.6)$ & $10(11.8)$ & \\
\hline
\end{tabular}

Note: The values are expressed in numbers and percentage ( $n$ (\%)). * Exact fisher test.

Reference intervals for normal subject: AST: $<40 \mathrm{UI} / \mathrm{l}$; ALT: <401UI//; GGT: $<60$ UI//; LDH: $<225$ UI//; Procalcitonine: Troponin: <14 ng/l; Lymphocyte count: 1241-

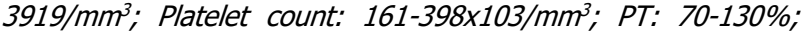
CRP<5 mg/l; Ferritin: $30-400 \mathrm{ng} / \mathrm{ml}$

\subsubsection{Therapeutic management and follow-up data}

Table 3 summarizes the therapeutic characteristics of our study population. Almost all of the patients were treated with hydroxychloroquine + azithromycin 
(98.1\%). 25\% experienced adverse reactions to the therapeutic protocol. The majority of patients with a healing time of less than 15 days were supplemented with vitamin $\mathrm{C}(97.6 \%)$ and zinc sulfate (95.3\%) showing a significant distribution according to the evolutionary data ( $p=0.048$ for vitamin $\mathrm{C}$ and $p<0.001$ for zinc sulfate). All of the patients transferred to the ICU did not take antiplatelet drugs and were undergoing antibiotic and oxygen therapies. The distribution according to the follow-up data and the healing time was significantly different $(p<0.001)$. On the other hand, we noted no statistically significant difference between treatment with corticosteroid $(p=0.058)$ and treatment with HBPM $(p=0.384)$.

Table 3. Patients' distributions according to therapeutic and follow-up data

\begin{tabular}{|c|c|c|c|c|}
\hline \multirow{2}{*}{ Variables } & \multicolumn{3}{|c|}{ Follow-up data $(n=108(\%))$} & \multirow[t]{2}{*}{$p^{*}$} \\
\hline & $\begin{array}{l}\text { Transfer } \\
\text { to ICU } \\
(n=5)\end{array}$ & $\begin{array}{l}\text { Healing } \\
\text { time }>15 \\
\text { days } \\
(n=18)\end{array}$ & $\begin{array}{l}\text { Healing } \\
\text { Time } \\
<15 \text { days } \\
(n=85)\end{array}$ & \\
\hline $\begin{array}{l}\text { Hydroxychloroqu } \\
\text { ine+Azithromyci } \\
\text { n }\end{array}$ & & & & 1.00 \\
\hline No & $0(0)$ & $0(0)$ & $2(2.4)$ & \\
\hline Yes & $5(100)$ & $18(100)$ & $83(97.6)$ & \\
\hline Vitamin C & & & & 0.048 \\
\hline No & $1(20)$ & $0(0)$ & $2(2.4)$ & \\
\hline Yes & $4(80)$ & $18(100)$ & $83(97.6)$ & \\
\hline Zinc sulfate & & & & $<0.001$ \\
\hline No & $4(80)$ & $0(0)$ & $4(4.7)$ & \\
\hline Yes & $1(20)$ & $18(100)$ & $81(95.3)$ & \\
\hline Paracetamol & & & & 0.015 \\
\hline No & $2(40)$ & $17(94.4)$ & $77(90.6)$ & \\
\hline Yes & $3(60)$ & $1(5.6)$ & $8(9.4)$ & \\
\hline $\begin{array}{l}\text { Antibiotic } \\
\text { therapy }\end{array}$ & & & & 0.001 \\
\hline No & $0(0)$ & $15(83.3)$ & $67(78.8)$ & \\
\hline Yes & $5(100)$ & $3(16.7)$ & $18(21.2)$ & \\
\hline $\begin{array}{l}\text { Corticosteroid } \\
\text { therapy }\end{array}$ & & & & 0.058 \\
\hline No & $0(0)$ & $11(61.1)$ & $39(45.9)$ & \\
\hline Yes & $5(100)$ & $7(38.9)$ & $46(54.1)$ & \\
\hline Oxygen therapy & & & & $<0.001$ \\
\hline No & $0(0)$ & $15(83.3)$ & $75(88.2)$ & \\
\hline Yes & $5(100)$ & $3(16.7)$ & $10(11.8)$ & \\
\hline $\begin{array}{l}\text { Platelet } \\
\text { aggregation } \\
\text { inhibitor }\end{array}$ & & & & $<0.001$ \\
\hline No & $5(100)$ & $1(5.6)$ & $13(15.3)$ & \\
\hline Yes & $0(0)$ & $17(94.4)$ & $72(84.7)$ & \\
\hline LMWH & & & & 0.384 \\
\hline No & $1(20$ & $10(55.6)$ & $38(44.7)$ & \\
\hline Yes & $4(80)$ & $8(44.4)$ & $47(55.3)$ & \\
\hline
\end{tabular}

Note: The values are expressed in numbers and percentage ( $n$ (\%)). * Exact fisher test. LMWH: low molecular weight heparin

\section{Discussion}

The main objective of the current study was to evaluate data in a population of hospitalized COVID-19 positive patients based on selected epidemiological, clinical and paraclinical data at admission and to describe the principle of the therapeutic management. In particular, obesity, older age and disturbances of biological parameters namely lymphocytes, LDH and ferritin levels are the predictor characteristics of patients transferred to the ICU. Also, radiologic abnormalities had been reported in an important proportion of cases. The therapeutic approach and the follow-up protocol considered in our study had demonstrated its efficacy in the majority of studied subjects.

The findings of our study on the correlation between age, addiction to tobacco, and smoking history with the severity of the disease and the healing time are similar to results were reported by the study of Wang et al., which showed that within 15 days of admission to hospital, patients $>65$ years and smoking-dependent have a higher risk of death, but unlike our study, these subjects have at least one comorbidity [32]. Similarly, a significant number of previously published reports confirm that age, smoking and the presence of chronic diseases, especially cardiovascular diseases directly are associated with the severity and the mortality of infected patients [33,34]. In the case of comorbidities, it was observed, in another study, that $86.8 \%$ of patients in non-severe condition and $84.9 \%$ of those with severity presented favorable results while unfavorable results were recorded in $80.8 \%$ of patients in critical situations [35]. However, for symptomatology contradictory results to ours have been found by other researches. Indeed, it was noticed that this variable is significantly pronounced in the nonsurvivors of infected patients. This was explained by proven respiratory failure as the main cause of death, followed by cardiac arrest and shock with proportions of $88.5 \%, 5.1 \%$ and $2.6 \%$ respectively [36].

Furthermore, the elevation of LDH, CRP and ferritinemia levels reported by our study, especially in patients transferred to the ICU, is also similar to the results reported by Wang et al., [36] with a decrease in lymphocytes that concerned $60 \%$ and $40 \%$ of the cases in our study. In this regard, high levels of CRP, LDH predisposition, and older age have been associated with the development of acute respiratory distress syndrome and presenting the main factors associated with ICU admission [37]. According to Zhou et al., these clinical characteristics were clearly developed in non-survivors in comparison with survivors [38]. Similarly, Chen et al have reported that different inflammatory markers, ALT, LDH, D-dimer as well as serum concentrations of proinflammatory and anti-inflammatory cytokines were significantly higher in cases with severe conditions [39].

As for our findings of radiological parameters on admission, similar results were reported by another study revealing that on admission, ground glass opacity was the most common radiological finding on chest CT scan $(56.4 \%)$ [40]. In this context, the study by Ling and colleagues reported opacity in $55.0 \%$ of non-severe patients, in $52.1 \%$ of patients in severe condition and in $26.9 \%$ of critical illness group. In addition, patients with unfavorable results are more likely to develop bilateral pulmonary consolidations and intraocular interstitial thickening [35]. However, another study showed that in all studied patients, abnormalities in chest CT images were detected [41]. In terms of cardiovascular disease, our results clearly reported that the duration of the disease is minimal in cases showing no cardiac complications. Research carried out in this direction showed several disparities. Indeed, some previous studies have found that this symptom has rarely been observed in patients with SARS-Cov-2 infection $[41,36,42]$. However, other studies have reported 
evidence of heart damage in some COVID-19 patients [43]. Further, cardiac complications are common in patients with pneumonia related to older age and prior existence of cardiac disorders [44,45]. They are also associated with negative influenza outcomes and other respiratory viral infections $[46,47]$.

Regarding the therapeutic approach, 98.1\% (106/108 subjects) of our patients were treated with hydroxychloroquine + azithromycin with a proportion of $25 \%$ who presented adverse drug reactions. Worldwide, the positive effect of this drug has been proven by different researches. Moreover, hydroxychloroquine has been widely recommended as a drug against COVID-19 on the basis of its antiviral effect on SARS-Cov-2 virus [48]. In a cohort of 2541 patients who followed a therapeutic protocol including chloroquine, hydroxychloroquine and azithromycin, a sharp decrease in mortality and in the risk of transfer to ICU was observed. This treatment has been found to be highly effective when given in the first days of infection and before its aggravation [12,49]. Another study has shown that treatment with hydroxychloroquine is effective within three to six days [50]. Moreover, preliminary results obtained from more than 100 patients showed the apparent efficacy of chloroquine in terms of reducing the exacerbation of pneumonia, duration of symptoms and accelerating virus clearance, with no severe adverse drug reactions [51]. Therefore, chloroquine has been included in the recommendations for the prevention and treatment of COVID-19 pneumonia [51]. Importantly, results of a recently published study showed that the early treatment with the combination of hydroxychloroquine and azithromycin are effective in viral clearance resulting in early discharge of COVID-19 patients [52]. However, in the context of the Solidarity trial conducted by the WHO which closed the hydroxychloroquine component last July, contradictory results have been reported. Indeed, several previously published observational studies have shown the ineffectiveness of the use of hydroxychloroquine in the treatment of COVID-19 and even the absence of a beneficial effect of hydroxychloroquine in hospitalized patients $[53,54]$. It was also assessed that this therapeutic approach could increase the need for invasive mechanical ventilatory assistance and it is associated with an increase in the length of hospitalization [55]. Similarly, the RECOVERY study, conducted in 4717 patients, found no difference in 28-day mortality between the group who received hydroxychloroquine in addition to standard treatments and the group who received standard treatment alone [56].Clearly, more studies with specific and well defined parameters are needed to establish the efficacy of this drug for Covid-19 treatment.

Currently, in the absence of specific treatment for this new virus, it is urgent to find an alternative solution to prevent and control its replication and its spread. Strengthening the immune system seems to present an important alternative. Thus, an optimal immune response relies on proper diet and nutrition to prevent infection. Facing a COVID-19 infection, several micronutrients are, therefore, are concerned. In our case, the supplementation with vitamin $\mathrm{C}$ and zinc was considered showing an important role in decreasing the healing time less than 15 days in the majority of. Additionally, the combination of zinc and pyrithione at low concentrations inhibits the replication of the SARS coronavirus (SARS$\mathrm{CoV}$ ) by decreasing COVID-19-related symptoms like diarrhea and lower respiratory infection [57]. Interestingly, in a series of cell culture experiments, Panchariya and colleagues reported that the ionic form of zinc alone inhibits the enzymatic structure SARS-CoV-2 Mpro following the formation of a stable complex, using two water molecules, at the active site of the virus [58].

For vitamin $\mathrm{C}$, the team of Lio et al. reported that high-dose intravenous vitamin $\mathrm{C}$ could be an effective treatment choice in the early stages of COVID-19 by strengthening the alveolar epithelial barrier. This molecule is also expected to improve lung function and reduce mortality of patients with COVID-19. This is supported by our study where $97 \%$ of the patients who received vitamin $\mathrm{C}$ supplementation recovered in less than 15 days [59].

Our study also included the use of corticoid therapy to treat severe inflammation in Covid-19 patients and $54 \%$ of patients with a healing time of less than 15 days received this therapy. In this context, a retrospective observational study of 309 adults with severe Middle East Respiratory Syndrome has shown that patients receiving corticosteroids were more likely to require mechanical ventilation, vasopressors, and renal replacement therapy [60]. Furthermore, for the management of SARS, corticosteroid therapy was more associated with psychosis, diabetes and avascular necrosis [60,42]. Routine corticosteroid use is even higher in critically ill patients with COVID-19 (up to $70 \%$ of these patients receive it) [60] for a possible positive effect in reducing lung abnormalities caused by inflammation [41]. Most importantly, in another study, patients treated with a corticosteroid had more clinical symptoms, a higher index of inflammation and more abnormalities on a chest CT scan, indicating that its use was related to the severity of symptoms during presentation [61]. On this basis, the current WHO Interim Guidelines for the Clinical Management of Severe Acute Respiratory Infection with Suspected SARS-CoV-2 infection advise against the use of corticosteroids except otherwise indicated for another reason [62].

The application of anticoagulants was also strongly considered in this study, especially the use of low molecular weight heparin that showed favorable results among our studied patients. This molecule has been commonly administered to COVID-19 because of its multiple effects, mainly the anti-inflammatory one $[63,18]$. This anticoagulant therapy has been recommended by various expert consensuses because of the risk of venous thromboembolism and intravascular coagulation [64]. However, more studies are needed to prove the beneficial action of this treatment [18].

This study presents some limitations which include the lack of a control group in order to assess the efficacy of hydroxychloroquine treatment. In addition, there was no follow-up of pulmonary changes after hospitalization. Finally, the correlation between the results of the radiological and histopathological diagnosis was not evaluated because the lung tissue biopsy not available.

\section{Conclusions}

This study shows that the minimal healing time of the patients is better in younger age group, the non- 
consumption of the tobacco, the manifestation of benign radiological and cardiac symptoms and, the presence of normal levels of the certain biological parameters. Most importantly, this work presents evidence of the beneficial effect of the adopted therapeutic and followup protocol as it provides new information to update data on epidemiological, clinical and evolutionary characteristics of patients infected with Sars-Cov-2 in Morocco. Thus, this study contributes to a better understanding of a unique situation in developing countries where lethality, critical cases and epidemiological situation seem to be more controlled than in developed countries.

Acknowledgments: Authors gratefully acknowledge all the patients who participate in this study, the medical staff and all health workers of the VINCI clinic. They would also like to thank all the authorities and partners involved in the research.

\section{References}

1. W. Yang, Q. Cao, L. Qin, X. Wang, Z. Cheng, A. Pan, et al. China J Infect. , 80(4), 388-393 (2020)

2. OM. Solmaz. International Journal of General Medicine, 13, 443-467 (2020). doi: 10.2147/IJGM.S263666

3. H. Benkirane, J. Heikel, FZ. Laamiri, A. Bouziani, H. Lahmam, A. Al-Jawaldeh, N. El Haloui, K. Ennibi, N. Akhtar-Khan, EM. El Fahime, M. Obtel, A. Barkat, and H. Aguenaou. Front. Physiol., 11, 595005 (2020). doi:10.3389/fphys.2020.595005

4. A. Hussain, J. Kaler, E. Tabrez, S. Tabrez and S Tabrez. Cureus. 18; 12(5):e8184 (2020).

5. D. Wang, B. Hu, C. Hu et al. JAMA, 323:1061. 10.1001/jama.2020.1585\} (2020)

6. M. Pepe, E. Maroun, R. Romero, R. Arroyo-Espliguero, I. Fernandez-Rozas, A. Aparisi, VM. Becerra-Munoz, MG Aguado, et al. Clinical and Experimental Medicine, 21:249-268 (2021).

7. P. Gautret, M. Million, PA. Jarrot, L. Camoin-Jau, P. Colson, F. Fenollar, M. Leone, B. La Scola, C. Devaux, JY. Gaubert, JL. Mege, J.Vitte, C. Melenotte, JM. Rolain, P. Parola, JC. Lagier, P. Brouqui, and D. Raoult. Expert Review of Clinical Immunology; 16. 12, 1159-1184 (2020).

8. JD. Goldman, DCB. Lye, DS. Hui; KM. Marks, R. Bruno, R. Montejano, CD. Spinner, M. Galli, MY. Ahn, RG. Nahass, YS. Chen, D. SenGupta, RH. Hyland, AO. Osinusi, et al. N Engl J Med, 5;383(19):1827-1837 (2020). doi: 10.1056/NEJMoa2015301

9. J. Xu and Y. Zhan. Complementary Therapies in Clinical Practice, 39, 101165 (2020).

10. RT. Gandhi, JB. Lynch, C. Del Rio. N Engl J Med. 29;383 (18):1757-1766 (2020). doi: 10.1056/NEJMcp2009249

11. P. Gautret, JC. Lagier, P. Parola, VT. Hoang, L. Meddeb, M. Mailhe, B. Doudier, J. Courjon, et al. Int J Antimicrob Agents. 56(1):105949 (2020)

12. S. Arshad, P. Kigore, Z.S. Chaudhry, G.Jacobsen, D.D. Wang, K. Huitsing, et al. Int J Infect Dis. (2020). doi:10.1016/j.ijid.2020.06.09

13. M. Million; JC. Lagier; P. Gautret; P. Colson; PE. Fournier; S. Amrane; M. Hocquart; M. Mailhe et al. Trav Med Infect Dis. 5:101738 (2020). https://doi.org/ 10.1016/j.tmaid.2020.101738

14. RECOVERY Collaborative Group., P. Horby, M. Mafham, L. Linsell, JL. Bell, N. Staplin, JR. Emberson, M. Wiselka, A.Ustianowski, E. Elmahi, B. Prudon, T. Whitehouse, T. Felton, J. Williams, Faccenda et al. N Engl J Med. 19;383(21):20302040 (2020). doi: 10.1056/NEJMoa2022926.

15. AB. Cavalcanti, FG. Zampieri, RG. Rosa, LCP. Azevedo, VC. Veiga,_A. Avezum, LP. Damiani et al. Hydroxychloroquine avec ou sans azithromycine dans le Covid-19 léger à modéré. N Engl J Med; 383: 2041-2052 (2020); Essai RECOVERY: RECOVERY Collaborative Group.

16. Y. Wang, D. Zhang, G. Du, R. Du, J. Zhao, Y.Jin, S. Fu, L. Gao, Z. Cheng, Q. Lu, Y. Hu, G. Luo, et al. Lancet; 395 (10236):1569-78 (2020); doi: 10.1016/S0140-6736(20)31022-9

17. B. Cao, Y. Wang, D. Wen et al. N Engl J Med; 382(9):1787-99 (2020).

18. A. Gasmi,; M. Peana,; S. Noor,; R. Lysiuk,; A. Menzel,; A. Gasmi Benahmed,; G. Bjørklund,. Applied Microbiology and Biotechnology; 105:1333-1343

https://doi.org/10.1007/s00253-021-11094-4

19. MT. Rahman and SZ Idid. Biological Trace Element Research; 199:550-558 (2021). https://doi.org/10.1007/s12011-020-02194-9

20. N. Ali. J Infect Public Health.;13(10):1373-1380 (2020). doi:10.1016/j.jiph.2020.06.021.

21. H. Harri and C. Elizabeth. Infect Chemother., 52(2), 222-223 (2020), https://doi.org/10.3947/ic.2020.52.2.222

22. D. Gao, M. Xu.; G. Wang, J. Lv, X. Ma, Y.Guo, Z D. hang, H. Yang, W. Jiang, et al. Aging (Albany NY); 13(5): 7020-7034 (2021). doi: 10.18632/aging.202557

23. I. Campi,; L. Gennari,; D. Merlotti,; C. Mingiano,; A. Frosali,; L. Giovanelli,; C. Torlasco,; MF. Pengo et al. BMC Infectious Diseases 21:566 (2021). https://doi.org/10.1186/s12879-021-06281-7

24. P. Sun,; S. Qie,; Z. Liu,; J. Ren,; K. Li,; J. Xi,. J Med Virol, 92(6), 612-7 (2020).

25. TM. Uyeki, HH. Bernstein, JS. Bradley, J. Englund, TM.AFile, AM. Fry et al. Clin Infect Dis Off Publ Infect Dis Soc Am., 68(6), e1-47 (2019).

26. N. Tang;; H. Bai,; X. Chen,; J. Gong; D. Li,; Z. J Thromb Haemost, 18, 1094-1099 (2020). doi: 10.1111/jth. 14817

27. J. Chen, P. Liudan, L. Liu, P. Liu, Q. Xu, L. Xia et al. Journal of Zhejiang University (Medical Edition), 2020, 49 (1), 0-0

28. V.M. Corman, O. Landt, M. Kaiser, R. Molenkamp, A. Meijer ; D-KW. Chu, et al. Eurosurveillance., 25, 3, 23 (2020). doi: 10.2807/1560-7917.ES.2020.25.3.2000045

29. World Health Organization. Physical Status: The Use and Interpretation of Anthropometry. Report of a WHO Expert Committee. Geneva: WHO (1995); http://www.apps.who.int/iris/bitstream/10665/3700 
3/1/WHO_TRS_854.pdf?ua=1. Accessed 7 July 2015.

30. M. Prokop, W. van Everdingen, T. van Rees, Vellinga et al. CO-RADS: A Categorical CT Assessment Scheme for Patients Suspected of Having COVID-19-Definition and Evaluation. Radiology;296(2):E97-E104 (2020)

31. Ministère de la santé (MSa). Mise à jour du protocole de prise en charge des cas COVID-19, de gestion de leurs contacts et de la stratégie du dépistage. Circulaire $\mathrm{N}^{\circ} 37,038,49$ et 50/DELM/00 du 06 Juillet (2020)

32. K. Wang, Z. Zhang, M. Yu, Y. Tao and M Xie. Intensive Care Med, 46, 1472-1474 (2020). https://doi.org/10.1007/s00134-020-06047-w

33. MR. Mehra, SS. Desai, SR. Kuy, TD. Henry and AN Patel. Cardiovascular Disease, Drug Therapy, and Mortality in Covid-19. N Engl J Med 2020; 382;2582. doi: 10.1056/NEJMoa2007621

34. JL. Nguyen, W. Yang, K. Ito, TD. Matte, J. Shaman, PL. Kinney. Seasonal influenza infections and cardiovascular disease mortality. JAMA Cardiol 1: 274-81 (2016).

35. L. Hu, S. Chen, Y. Fu, Z. Gao, H. Long, H. Ren, Y. Zuo, J. Wang et al. Clinical Infectious Diseases, 71(16):2089-2098 (2020). doi:10.1093/cid/ciaa539

36. D. Wang, B. Hu, C. Hu et al. JAMA; 17, 323(11), 1061-1069 (2020). doi:10.1001/jama.2020a.1585

37. J. Chen, T. Qi, L. Liu, Y. Ling, Z. Qian, T. Li, F. Li, Q. Xu, Y .Zhang, S. Xu, Z. Song, Y. Zeng, Y. Shen, Y. Shi, T. Zhu, and Lu H. Journal of Infection; 80, e1-e6 (2020).

38. F. Zhou, T. Yu, R. Du, G. Fan, Y. Liu, Z. Liu et al. The Lancet, 395, 1054-1062 (2020). https://doi.org/10.1016/ S0140-6736(20)30566-3

39. G. Chen, D. Wu, W. Guo et al. J Clin Invest., 130(5), 2620-2629 (2020). doi:10.1172/JCI137244

40. W. Guan, Z. Ni, Y. Hu, W. Liang, C. Ou, J. He, L. Liu, H. Shan et al. N Engl J Med, 382, 1708-20 (2020). doi: 10.1056/NEJMoa2002032

41. C. Huang, Y. Wang, X. Li, L. Ren, J. Zhao, Y.Hu, L. Zhang, G. Fan et al. Lancet, 395, 497-506 (2020). doi: 10.1016/S0140-6736(20)30183-5

42. X. Yang, Y. Yu, J. Xu, et al. Lancet Respir Med, (2020); published online Feb 24. https://doi.org/ 10.1016/S2213-2600(20)30079-5.

43. J. He, B. Wu, Y. Chen, J. Tang, Q. Liu, S. Zhou, C. Chen, Q. Qin, K.. Huang, J. Lv, Chen, Y. and Peng D. Canadian Journal of Cardiology; 36: 966.e1e966.e4 (2020) www.onlinecjc.ca

44. VF. Corrales-Medina, DM. Musher, S. Shachkina, and JA. Chirinos. Lancet; 381: 496-505 (2013)

45. JA. Udell, R. Zawi, DL. Bhatt et al. JAMA; 310: 1711-20 (2013)

46. R. Blackburn, H. Zhao, R. Pebody, A. Hayward and Warren-Gash, C. Clin Infect Dis; 67: 8-17 (2018)

47. CA. Devaux, J-M. Rolain, P. Colson, D. Raoult. Int J Antimicrob Agents, 55(5):105938 (2020).

48. S. Arshad, P. Kigore, Z.S. Chaudhry, G. Jacobsen, D.D. Wang, K. Huitsing, et al. Int J Infect Dis. 2020; https://doi.org/10.1016/j.ijid.2020.06.09
49. JC. Lagier, M. Million, P. Gautret, P. Colson, PE. Fournier, S. Amrane, M. Hocquart, M. Mailhe et al. Travel Medicine and Infectious Disease 36; 101791. (2020).

50. P. Gautret, J. Lagier, P. Parola, V. Hoang, L. Meddeb, M. Mailhe, B. Doudier, J. Courjon, V. Giordanengo, V. Vieira, H. Tissot Dupont, S. Honoré, P. Colson, E. Chabrière, B. La Scola, J. Rolain, P. Brouqui and Raoult, D. International Journal of Antimicrobial Agents, 56(1), p.105949 (2020).

51. J. Gao, Z. Tian, X. Yang. Biosci Trends, 14(1), 7273 (2020). doi: 10.5582/bst.2020.01047

52. P. Gautret, VT. Hoang, JC. Lagier and D. Raoult. Int J Antimicrob Agents. Jan; 57(1): 106239 (2021). doi: 10.1016/j.ijantimicag.2020.106239

53. ES. Rosenberg, EM.Dufort, T. Udo, LA. Wilberschied,; J. Kumar; J. Tesoriero, et al. JAMA, 23; 323(24):2493-2502 (2020).

54. Haut conseil de la santé publique (HCSP). Rapport relatif à l'actualisation de la prise en charge des patients atteints de Covid-19. 23 juillet (2020)

55. J. Barbosa, D. Kaitis, R. Freedman, K. Le, X. Lin, Submitted to the New England Journal of Medicine 2020

56. RECOVERY Collaborative Group; P. Horby, M. Mafham, L. Linsell, JL. Bell, N. Staplin, JR. Emberson, et al. N Engl J Med. 19; 383(21):20302040 (2020). doi: 10.1056/NEJMoa2022926

57. AJW. te Velthuis, SHE. van den Worm, AC. Sims, RS. Baric, EJ. Snijder, MJ. van Hemert. PLOS Pathog. ; 6:e1001176 (2010).

58. L. Panchariya, WA. Khan, S. Kuila, K. Sonkar, S. Sahoo, A. Ghoshal, A. Kumar, DK. Verma, A. Hasan, S. Das, JK.Thakur, R.Halder, S.Sunil, A. Arockiasamy,. 2021. https://doi.org/10.1101/2021.06.15.448551

59. F. Liu, Y. Zhu, J. Zhang et al. BMJ Open; 10:e039519 (2020).

60. D.T.Lee, Y.K.Wing, H.C.Leung, J.J.Sung, Y.K. Ng,; G.C. Yiu et al. Clin Infect Dis, 39, pp. 1247-1249 (2004)

61. L.Zha,; S.Li,; L.Pan,; B.Tefsen,; Y.Li,; N.French,; L. Chen,; G. Yang, and EV. Villanueva. The Medical Journal of Australia.; 212(9):416-420 (2020). doi: 10.5694/mja2.50577

62. World Health Organization. Clinical management of severe acute respiratory infection when novel coronavirus (2019-nCoV) infection is suspected: interim guidance, 28 January. World Health Organization;(2020). https://apps.who.int/iris/handl e/10665/330893

63. TJ. Poterucha, P. Libby and SZ. Goldhaber, Thromb Haemost. 117(3):437-444 (2017)

64. Shanghai Clinical Treatment Expert Group for COVID-19. Comprehensive treatment and management of coronavirus disease 2019: expert consensus statement from Shanghai (in Chinese). Chin J Infect Dis. (2020) 